\title{
Quantitative correlation between cellular proliferation and nuclear poly (ADP-ribose) polymerase (PARP-1)
}

\author{
ERNEST KUN ${ }^{1,2}$, EVA KIRSTEN ${ }^{1}$, PAL I. BAUER $^{3}$ and CHARLES P. ORDAHL ${ }^{1}$ \\ Departments of ${ }^{1}$ Anatomy, and ${ }^{2}$ Cellular and Molecular Pharmacology, School of Medicine, \\ University of California San Francisco Medical Center, San Francisco, CA 94143, USA; \\ ${ }^{3}$ Department of Medical Biochemistry, Semmelweis University, Budapest, Hungary
}

Received September 12, 2005; Accepted October 24, 2005

\begin{abstract}
Treatment of cells with lysophosphatidyl choline and centrifugal extraction can separate poly (ADP-ribose) synthetase (PARP-1) and DNA synthetase activities, permitting the experimental analysis and comparison of both multienzyme systems. Only PARP-1 is being assayed by our system. $\mathrm{Ca}^{2+}$ and $\mathrm{Mg}^{2+}$ have minor activating effects, and added histones are without activating action. Short end-blocked dsDNAs at $\mathrm{nM}$ concentrations and spermine at $\mathrm{mM}$ concentrations are maximally activating coenzymes of poly (ADP-ribose) synthesis. Comparison of non-proliferating non-malignant cells with rapidly growing cancer cells demonstrates that rates of poly (ADP-ribose) synthesis and DNA synthesis are highest in pre-confluent non-malignant cells and in proliferating cancer cells, and lowest in contact-inhibited non-malignant cells. Rates of poly (ADP-ribose) synthesis correlate with the number of enzymatically activable PARP-1 molecules per cell, determined under $\mathrm{V}_{\max }$ conditions where activity is linearly proportional to enzyme protein. Contact-inhibited non-malignant cells exhibit only trans-ADP-ribosylation that is not affected by ATP, while rapid growth, especially in cancer cells, demonstrates extensive auto-poly (ADP)-ribosylation that is strongly inhibited by ATP at concentrations present in cells exhibiting normal bioenergetics. Rates of mRNA synthesis in non-proliferating nonmalignant cells and in cancer cells were indistinguishable, indicating that the differences observed between cellular
\end{abstract}

Correspondence to: Professor Ernest Kun or Professor Charles P. Ordahl, Department of Anatomy, School of Medicine, University of California San Francisco Medical Center, San Francisco, CA 94143, USA

Abbreviations: PARP-1, poly (ADP-ribose) polymerase-1 (EC 2.4.2.30), also poly (ADP-ribose) synthetase; LL, lysophosphatidyl choline (lysolecithin); PAR, poly (ADP-ribose); IEF, isoelectric focusing; $\mathrm{INH}_{2} \mathrm{BP}$, 5-iodo-6-amino-1,2-benzopyrone; AT, end protected homopolymer ( $\mathrm{n}=23$ ); ADP-HPD, adenosine diphosphate (hydroxy-methyl) pyrrolidine diol; $\mathrm{INO}_{2} \mathrm{BA}$, 4-iodo-3-nitrobenzamide

Key words: lysophosphatidyl choline permeabilized cell fractionation of PARP-1 and DNA synthetase systems, PARP-1 mRNA analysis, control of DNA synthesis by PARP-1 activity, AMP-PNP phenotypes are most likely due to reassembly of PARP-1 molecules in nuclei to homo-dimers (in cancer cells) and hetero-dimers (in non-cancer cells). A specific inhibitor and an inactivator of PARP-1 each inhibit DNA synthesis when intact cancer cells are pretreated with these drugs. Direct addition of these drugs to permeabilized cells performing DNA synthesis has no effect on DNA synthesis. The most striking diagnostic signal for cancer cells is activation of PARP-1 and of DNA synthesis.

\section{Introduction}

We have developed two specific ligands of PARP-1 which by distinct biochemical mechanisms inactivate or inhibit this enzyme. The first reagent is $\mathrm{INO}_{2} \mathrm{BA}(1)$, which is selectively reduced by cancer cells to the nitroso compound (INOBA), that avidly reacts with the asymmetric $\mathrm{Zn}^{2+}$ finger of PARP-1 (and of DNA ligase III), thereby inactivating these enzymes and inducing selective death in cancer cells. Since in normal cells the reduction of $\mathrm{INO}_{2} \mathrm{BA}$ proceeds to the amino compound $\mathrm{INH}_{2} \mathrm{BA}$, which is an innocuous molecule, the tumoricidal action, primarily mediated by PARP-1, predestines $\mathrm{INO}_{2} \mathrm{BA}$ to serve as a selective anticancer drug. The second ligand $\mathrm{INH}_{2} \mathrm{BP}(2)$ in part competes with NAD at the NAD binding site of PARP-1, sharing this property with a large number of 'NAD-site' oriented drug candidates (3). However, a second dimension of $\mathrm{INH}_{2} \mathrm{BP}-\mathrm{PARP}-1$ interaction has recently been identified (4), involving arginine 34 in the $\mathrm{Zn}^{2+}$ finger 1 domain of PARP-1, an interaction which significantly distinguishes $\mathrm{INH}_{2} \mathrm{BP}$ from other PARP-1 ligands (3) that by themselves have no effect on malignant cells (5). It is of further importance that all rapidly growing cancer cells so far tested respond to both $\mathrm{INO}_{2} \mathrm{BA}$ and $\mathrm{INH}_{2} \mathrm{BP}$ (US patent pending; Kun et al, Treatment of Cancer, BiPar Sciences Inc., no. 718,101, 2005); thus it appears that a salient phenotypic characteristic, unrelenting growth and multiplication (6), is affected by these PARP-1 ligands. Thus we can conclude that PARP-1 may play a fundamental role in all rapidly growing cancers, a working hypothesis pursued in the present report. It also follows that the study of 'rapid' cancer growth avoids the involvement of clearly multitudinous phenotypes of many cancers (6) and simplifies our inquiry into the analysis of growth characteristics, regardless of the origin of cancers. 
Based on sequence homology and the activation by randomly broken DNA a 'PARP-superfamily' has been invoked (7), which raises an important question: which of the PARPs plays a role in growth regulation. As documented here, we show that our PARP-1 assays $(8,9,12)$, utilizing specific DNAs and spermine as activators, can detect only PARP-1, and thus the patho-physiologic role of other PARPs is delegated to other cellular biochemical domains.

In the preceding studies, we confined our experiments to the purified or cloned PARP-1; therefore, these results can be at best considered as models for integrated cellular studies.

As we demonstrate here, treatment of cells with lysophosphatidyl choline (lysolecithin, abbreviated as LL) provides an experimental cell model in which PARP-1, just as in intact cells, is nuclear structure-associated (2). Significant differences between the regulation of the pure enzyme in solution and the structure-associated PARP-1 in LL-treated cells were noted. In contrast to PARP-1 in solution $(8,9,12)$, the LL preparation did not respond to added histones, as would be expected from an intracellular association of PARP-1 with nucleosomes. Furthermore, the LL preparations were nearly insensitive to added $\mathrm{Ca}^{2+}$ and $\mathrm{Mg}^{2+}$, and enzymatic activity in cancer cells was strongly stimulated by dsDNAs at nM concentrations. Here, the cationic requirement of PARP-1 was confined to spermine as an activator, confirming previous results $(2,9)$ that link PARP-1 to polyamine metabolism.

Perhaps the most striking phenomenon observed in our present studies is a correlation between cellular proliferation and PARP-1 activity. Inhibition of PARP-1 following treatment of cells with a reversibly acting drug (2) or a covalently inactivating prodrug $\left(\mathrm{INO}_{2} \mathrm{BA}\right)$ (1) inhibited both PARP-1 activity and DNA synthesis, indicating a novel correlation between PARP-1 and malignant cell proliferation.

\section{Materials and methods}

Cell permeabilization for the assay of PARP-1 activity and for DNA synthesis. This method is an adaptation of a previously reported procedure (2) which is based on the technique published in 1978 and $1980(10,11)$. Cell permeabilization by a solution of lysophosphatidyl choline (LL) differs from other procedures which employ hypotonic salt solutions and (or) detergents inasmuch as LL-treated cells retain their nuclear ultrastructure as determined by electron microscopy $(2,10,11)$. Contact-inhibited non-malignant cells from a $10 \mathrm{~cm}$ tissue culture dish $\left(5-8 \times 10^{6}\right)$ were harvested by trypsinization, washed once with $1 \mathrm{ml}$ solution A (150 mM sucrose, $80 \mathrm{mM}$ $\mathrm{KCl}, 35 \mathrm{mM}$ HEPES $\mathrm{pH}$ 7.4), and for DNA synthesis, $5 \mathrm{mM}$ $\mathrm{MgCl}_{2}+0.5 \mathrm{mM} \mathrm{CaCl}_{2}$ were added, then resuspended in cold solution A to give a total volume of $157 \mu 1$, to which $43 \mu 1$ of $1 \mathrm{mg} / \mathrm{ml}$ lysophosphatidyl choline (LL) in solution A was added, mixed and kept cold in ice (5 min). Malignant cells of course - did not exhibit contact inhibition. All permeabilized cells were trypan blue positive. To test PARP-1 activity, to this permeabilized cell suspension another $157 \mu 1$ solution A + $43 \mu 1 \mathrm{LL}$ in solution A (see above) were added, and the cells were sedimented by centrifugation in an Eppendorf tube in the cold, and the pellet resuspended in $200 \mu 1$ of the same medium. This washing step was omitted when DNA synthesis was measured. Both PARP-1 activity and DNA synthesis assays were carried out in individual $50 \mu 1$ incubations (in Eppendorf tubes) containing $20 \mu 1$ each of cell suspension $\left(\sim 0.6 \times 10^{6}\right.$ cells $)$, with additions as indicated in the figure legends, and the reactions were started by addition of $20 \mu 1$ of a) or b) which had the following composition: a) for PARP activity: $125 \mathrm{mM}$ Tris- $\mathrm{HCl}$ ( $\mathrm{pH}$ 7.3), $7.5 \mathrm{mM}$ dithiothreitol and $250 \mu \mathrm{M}$ NAD containing [ $\left.{ }^{32} \mathrm{P}\right]-\mathrm{NAD}$ (Amersham) to yield $\sim 50 \times 10^{6} \mathrm{dpm} / \mathrm{ml}$; and b) for DNA synthesis: $150 \mathrm{mM}$ sucrose, $80 \mathrm{mM} \mathrm{KCl}, 35 \mathrm{mM}$ HEPES (pH 7.4), $5 \mathrm{mM} \mathrm{MgCl}, 0.5 \mathrm{mM}$ $\mathrm{CaCl}_{2}, 50 \mathrm{mM}$ phosphoenolpyruvate, $3.12 \mathrm{mM}$ ATP, $0.25 \mathrm{mM}$ CTP, GTP and UTP each, $0.625 \mathrm{mM}$ dATP, dCTP, dGTP and dTTP each, and [32P]-dCTP (NEN, $6000 \mathrm{Ci} / \mathrm{mmol})$ to yield approximately $50 \times 10^{6} \mathrm{dpm} / \mathrm{ml}(10)$.

For maximal rates of DNA synthesis, $10 \mu \mathrm{l}$ of DNAase treated DNA $(1 \mu \mathrm{g} / \mathrm{ml})$ was also added as DNA template. After incubation (10 min at room temperature for PARP activity and $20 \mathrm{~min}$ at room temperature for DNA synthesis) the reactions were stopped by adding $1 \mathrm{ml}$ of cold $\left(4^{\circ} \mathrm{C}\right) 20 \%$ TCA followed by the addition of $50 \mu 1$ of $10 \mathrm{mg} / \mathrm{ml}$ solution of BSA as co-precipitant, and acid-precipitable radioactivity was determined $(2,12)$.

Two dimension gel electrophoretic characterization of endogenously formed poly ADP-ribosylated proteins. Cells were collected by trypsinization from a $12 \mathrm{~cm}$ culture dish, washed twice in PBS and sedimented. The cell number was determined in a hemocytometer. Four million cells were extracted with $0.2 \mathrm{ml}$ rehydration buffer (containing $2 \mathrm{M}$ thiourea, $7 \mathrm{M}$ urea, $2 \%$ CHAPS, $0.2 \%$ biolyte $\mathrm{pH} \mathrm{3-10}$, and $100 \mathrm{mM}$ DTT) to which protease inhibitors (Pierce), $10 \mu \mathrm{g}$ RNAase and 300 units Benzonase (both from Sigma) were added just before homogenization. Cells were homogenized in a tissue grinder (Amersham) and centrifuged. The supernatant was saved and the sediment re-extracted with $0.2 \mathrm{ml}$ rehydration buffer. The extracts were pooled and centrifuged for $20 \mathrm{~min}$ at $12000 \mathrm{rpm}$, at room temperature.

IEF strips (Bio-Rad, $11 \mathrm{~cm}, \mathrm{pH} 3-10$, non-linear gradient) were rehydrated in $200 \mu 1$ rehydration buffer containing $200 \mu \mathrm{g}$ protein (extract from $10^{6}$ cells) overnight at $50 \mathrm{~V}$ with the active rehydration program of IEF cells (Bio-Rad). The strips were covered with mineral oil ( $2 \mathrm{ml} / \mathrm{strip})$. Paper wicks wetted with $9 \mu 1$ water were placed between the electrodes and the IEF strip, and IEF was carried out according to the following program: $250 \mathrm{~V}$ for $25 \mathrm{~min}$ and linear increase of voltage to $8000 \mathrm{~V}$ in $2.5 \mathrm{~h}$. Finally this voltage was kept for $20000 \mathrm{~V} / \mathrm{h}$. The current was limited to $50 \mu \mathrm{A} /$ strip and the temperature was kept at $20^{\circ} \mathrm{C}$. The strips were removed, carefully wiped to remove oil, and kept at $-80^{\circ} \mathrm{C}$, gel side up.

Before electrophoresis the SDS-PAGE strips were treated twice with $2 \mathrm{ml}$ of equilibration buffer I at room temperature (6 M urea, 2\% DTT, $0.375 \mathrm{M}$ Tris- $\mathrm{HCl} \mathrm{pH} 8.8,30 \%$ glycerol) and twice with $2 \mathrm{ml}$ equilibration buffer II (containing $2.5 \%$ iodoacetamide instead of DTT). Each treatment lasted $10 \mathrm{~min}$ with shaking. Then strips were washed with electrophoresis running buffer and placed vertically over the gel (Criterion gel form, Bio-Rad, 4-15\% polyacrylamide gradient in Tris$\mathrm{HCl})$ and overlayed with low melting agarose $(0.4 \%)$. Electrophoresis was carried out with $200 \mathrm{~V}$ constant charge for $1 \mathrm{~h}$.

Proteins were transblotted onto PVDF membrane, and membranes blocked in $2.5 \%$ milk in PBS. Blots were 
soaked in the first antibody solution (either PAR or PARP-1 antibodies from Biolmol; 2000- and 1000-fold dilution, respectively) overnight, washed five times with $1 \%$ milk containing PBS plus $0.01 \%$ Tween-20 solutions $(25 \mathrm{ml}$ each washing) and incubated with HPO labeled second antibody for $2 \mathrm{~h}$ (2500-fold dilution). Visualization was done by ECL.

Quantitative PCR for PARP-1 mRNAs. Total RNA was isolated from 2 million Calu lung cancer and CV-1 cells using the Aurum system of Bio-Rad. RNA $(1 \mu \mathrm{g})$ was converted to cDNA with the use of the iScript kit of Bio-Rad, and $2.5 \mu 1$ of each reverse transcribed sample were analyzed by quantitative PCR (Bio-Rad, iQ SYBR Green). The primers were: GAA GCTCAGAGAGAACCCATCC and AAGCTCTACGAGTC GAGTACG, and DNA polymerase was activated by incubating wells at $95^{\circ} \mathrm{C}$ for $5 \mathrm{~min}$, followed by 35 cycles $(0.5 \mathrm{~min}$ at $94^{\circ} \mathrm{C}, 0.5 \mathrm{~min}$ at $58^{\circ} \mathrm{C}$ and $1 \mathrm{~min}$ at $72^{\circ} \mathrm{C}$ ). Quantitative assessment of mRNAs formed in CV-1 and Calu 6 cells was based on the application of known quantities of L19 gene (small ribosomal protein subunit, $180 \mathrm{bp}$, GGACAGAGTC TTG with ATCTC and CTGAAAGGGAATGTG primers) as internal standards.

Poly (ADP-ribose) polymerase catalyzed auto- and transpoly-ADP ribosylation reactions were assayed as described $(9,12)$. E-ras cells, CV-1 cells, human lung epithelial cells and lung cancer cells (Calu 6) were cultured as reported $(2,12)$. Cloned PARP-2 and PARP-3 proteins were obtained from AXXORA Co. (San Diego, CA, lot nos. ALX 201-064 and 201-170).

\section{Results}

Identification of PARP-1 as the sole enzyme detected by our enzyme assays. It would be anticipated that in permeabilized cells all PARP isoenzymes would be present (7). For this reason it was mandatory to establish which isoenzyme is being determined by our catalytic assay $(8,9,12)$. With AT as coenzymic DNA and spermine as activator, only PARP-1 was detectable as $\mathrm{V}_{\max }$ (e.g. at $8.0 \mathrm{nM}$ enzyme protein concentration) while PARP-2 and PARP-3 gave negative results at enzyme protein concentrations: $8.0 \mathrm{nM}$ for PARP-1, $0.8 \mathrm{nM}$ for PARP-2 and 3 at concentrations deduced from published results (13; data not shown). In summary, whereas all PARP isoenzymes were activated by damaged or broken DNAs (in the presence of $\mathrm{Mg}^{2+}$ or histones), only PARP-1 responded to $\mathrm{AT}+$ spermine as activator, which makes this assay a PARP-1 specific test $(8,9,12)$. In agreement with our enzymological results, fibroblasts of PARP-1/- mice, when tested by the LL method, yielded only trace amounts (1\%) of PARP-1 content, identified as such by the inhibition by ATP.

PARP-1 and DNA synthetase activity of LL-treated cells. In agreement with earlier reports (2), cells treated with LL retain their ability to synthesize poly (ADP-ribose) and DNA. However, a significant separation of these activities was achieved by washing of the cells with the LL solution. Without the washing step both PARP-1 and DNA synthetase activities were fully active. After one or two centrifugal washings only PARP-1 activity was quantitatively retained in
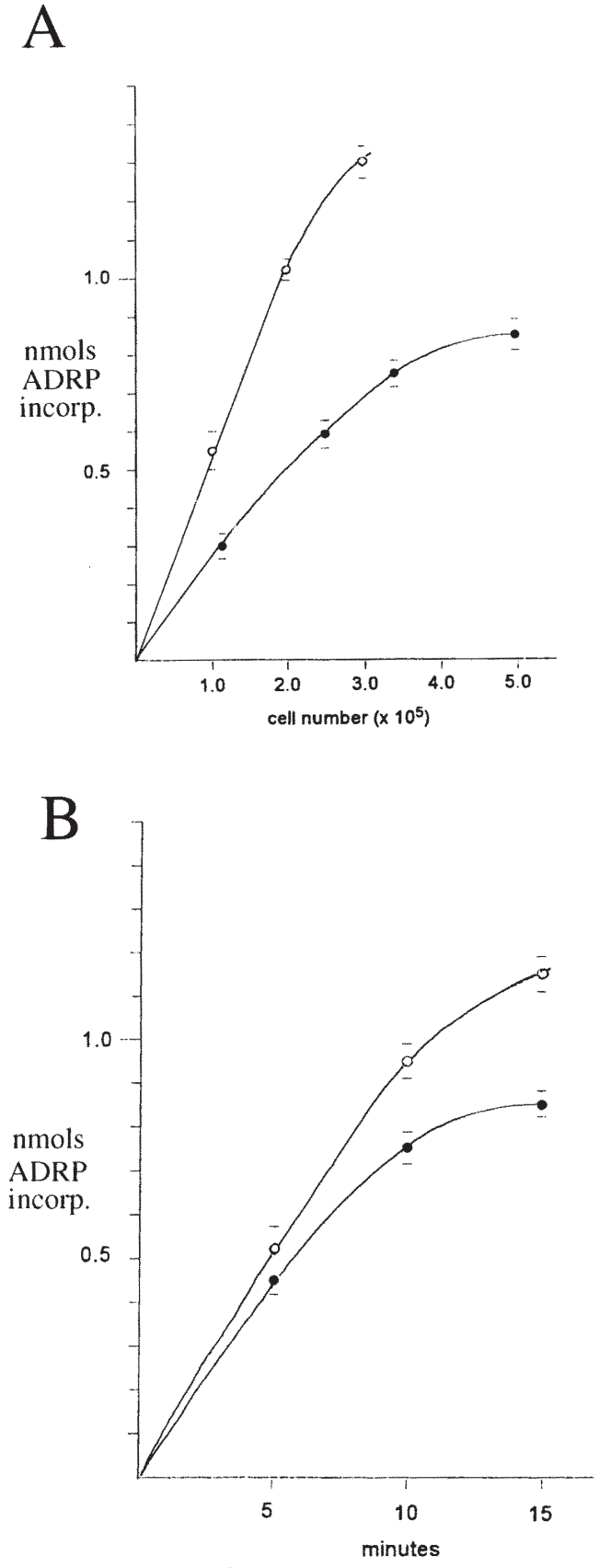

Figure 1. (A) The effect of cell number per assay on rates of incorportion of ADPR in 10 min. Open circles, E-ras; closed circles, Calu 6. Enzymatic assays were performed as described in Materials and methods with $3 \mathrm{mM}$ spermine and $100 \mathrm{mM}$ AT as cofactors in a test volume of $50 \mu 1$. (B) The influence of time of incubation of $0.3 \times 10^{6}$ cells on rates of incorporation of ADPR, as specified in (A). In both (A) and (B) mean values of triplicate assays are shown where deviations are indicated.

the centrifugal sediment and the DNA synthetase function was progressively lost, indicating a physical separation of the two multienzyme systems.

The quantitative relationship between the number of permeabilized cells and rates of poly (ADP-ribose) synthetase activity is shown in Fig. 1. A close to linear correlation between cell number and reaction rates is obtained between 0 and $3.0 \times 10^{5}$ cells per assay (Fig. 1A). At a fixed concentration of cells the $10 \mathrm{~min}$ (Fig. 1B) rates were nearly 
A

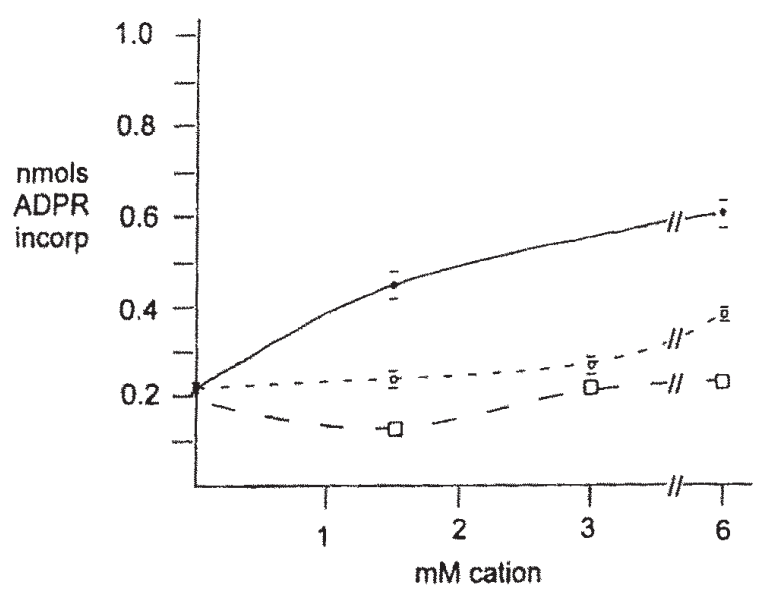

B

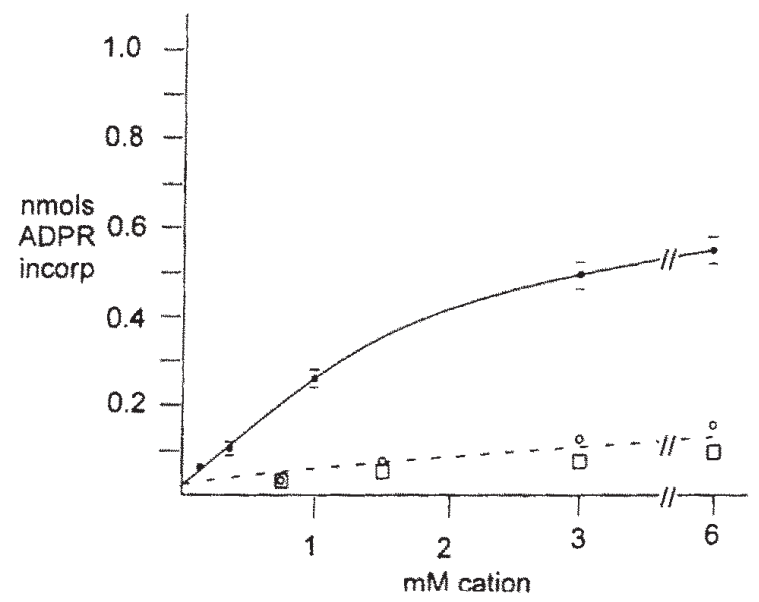

C

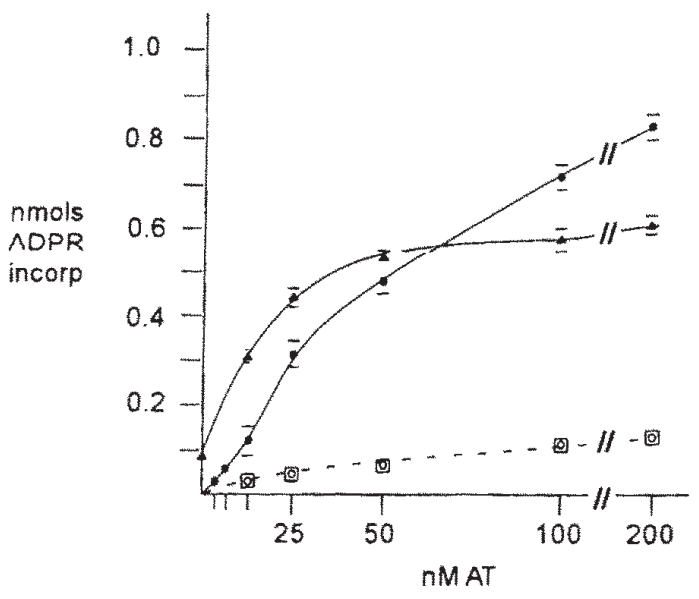

Figure 2. (A) The effect of spermine (solid circles), $\mathrm{Ca}^{2+}$ (open circles) and $\mathrm{Mg}^{2+}$ (open squares) at fixed concentration $(50 \mathrm{nM}) \mathrm{AT}$ are illustrated. Cell number (E-ras cells) per test was $0.3 \times 10^{6}$ (Fig. 1B). Mean values of triplicate tests are given, where deviations from the mean did not exceed $\pm 10 \%$. (B) Same as (A), except cells were Calu 6. Values obtained with $\mathrm{Ca}^{2+}$ and $\mathrm{Mg}^{2+}$ nearly coincided. (C) Comparison of the effects of the concentrations of added AT (nM) in the presence of $3 \mathrm{mM}$ spermine (top curves) or replacing spermine by histone $\mathrm{H}_{1}(25 \mu \mathrm{g} / 50 \mu \mathrm{l}$ per assay) (lower curve). Closed triangles, E-ras cells; closed circles, Calu 6. Open squares, E-ras; and open circles, Calu 6 where spermine has been replaced by histone $\mathrm{H}_{1}$. Triplicate assays, where variation of results was the same as in (A) and (B).

linear when tested with two species of cancer cells. The possible interference of poly (ADP-ribose) glycohydrolase (PARG) was tested in CV-1 and E-ras 20 cells by repeating the experiments shown in Fig. $1 \mathrm{~B}$ in the presence of $1 \mu \mathrm{M}$ of

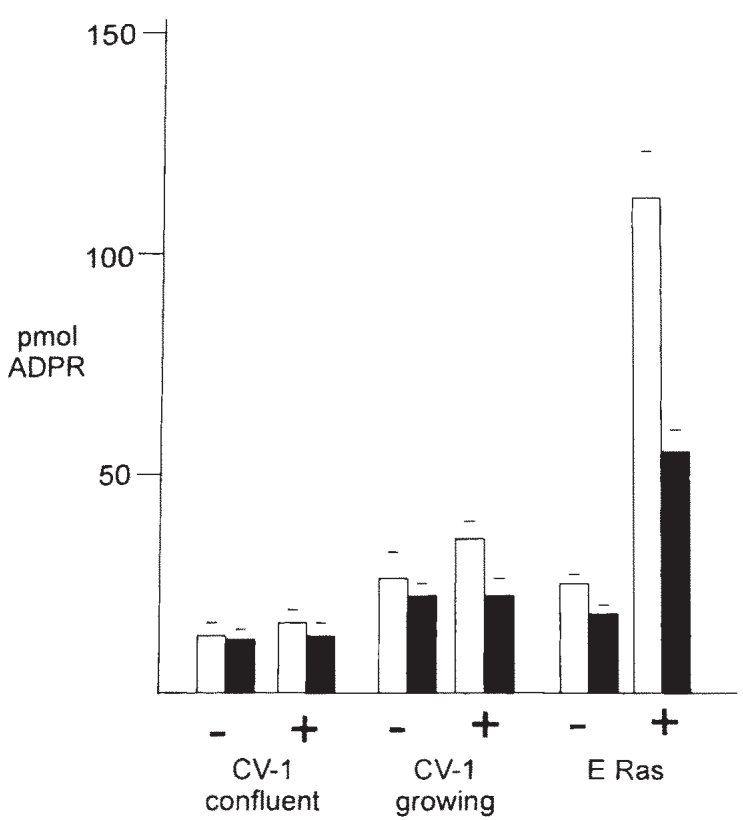

Figure 3. Immediately after permeabilization and washing, confluent or nonconfluent CV-1 or E-ras cells $\left(0.4 \times 10^{6}\right)$ were incubated with or without $50 \mathrm{nM}$ AT and/or the non-hydrolyzable ATP analog AMP-PNP (10 mM). Reaction rates were determined for $10 \mathrm{~min}$. Open bars, no AMP-PNP; shaded bars, + 10 mM AMP-PNP; +, added AT (100 nM); -, no AT. Triplicate assays, error bars.

a highly potent $\left(\mathrm{I}_{50}=0.33 \mu \mathrm{M}\right)$ PARG inhibitor, adenosine diphosphate (hydroxymethyl) pyrrolidine diol $(14,15)$. No effect of $1 \mu \mathrm{M}$ PARG inhibitor could be seen in triplicate kinetic assays (data not shown), demonstrating that there was no interference by PARG in the $10 \mathrm{~min}$ tests, as conducted throughout [ADP-HPD was obtained from Calbiochem (La Jolla, CA), cat no. 118415]. A more explicit study of the regulation of PARG in the LL system is the subject of ongoing research.

The same kinetic data were obtained with non-malignant cells as demonstrated for E-ras and Calu 6 cells except rates of growth of cancer cells were significantly higher (see below).

The effect of components of the assay system were further determined. Among the cations tested, spermine exerted the largest activation (top curve), and $\mathrm{Ca}^{2+}$ and $\mathrm{Mg}^{2+}$ had much smaller effects (Fig. 2A, Calu 6 cells). In E-ras cells (Fig. 2B) some PARP-1 activity could be detected without added cations. Fig. 2C illustrates the effect of varied concentrations of AT on PARP activity in LL preparations of Calu 6 cells and E-ras cells in the presence of $3 \mathrm{mM}$ spermine (solid symbols) or of histone (open circles, Calu 6 cells), or no cations (open squares, Calu 6 cells). It appears that the activity without any AT (end-protected 23mer) was slightly higher in E-ras cells compared to Calu 6 cells $(0.9$ pmols/10' vs 100 pmols in the latter). While spermine, $\mathrm{Mg}^{2+}$ and $\mathrm{Ca}^{2+}$ had marked cooperative effect on purified PARP-1 in solution (9), no evidence of cooperativity was detected in LL preparations (Fig. 2A and B).

Correlation between cellular prolifertion and PARP-1 activity of $C V-1$ and E-ras 20 cells. Rates of poly (ADP-ribose) synthesis in LL treated cells were compared in three groups: a) confluent non-proliferating $\mathrm{CV}-1$ cells, b) non-confluent 


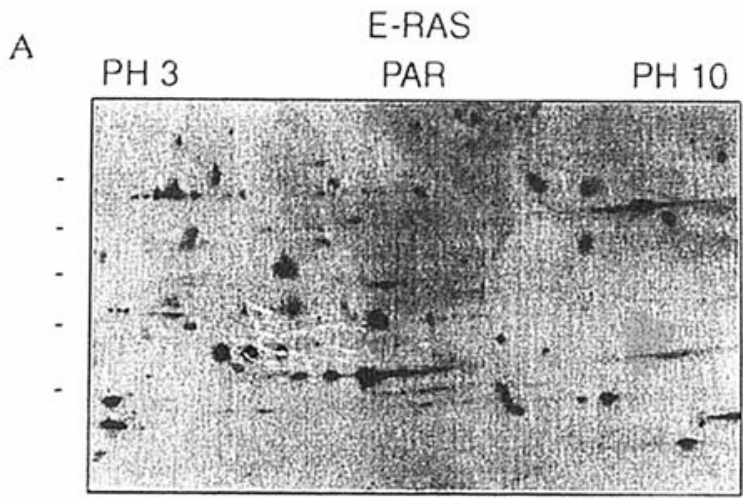

B

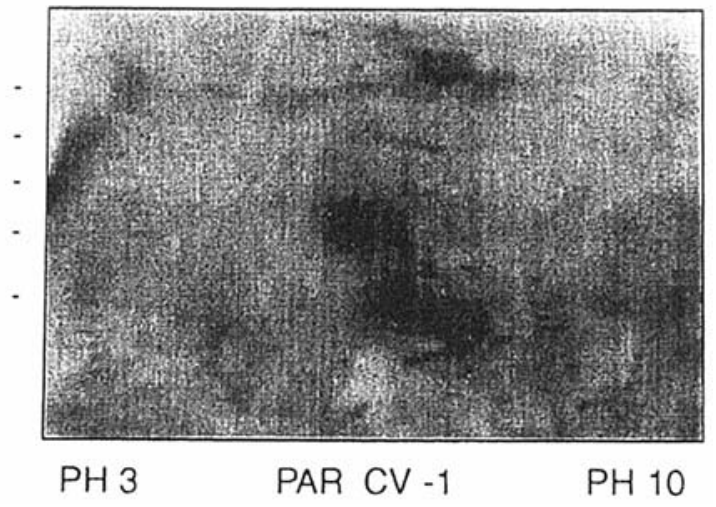

Figure 4. 2D gel electrophoresis of protein extracted from E-ras and contact inhibited (confluent) CV-1 cells (see Materials and methods). ADPR was visualized with PAR-antibody.

multiplying CV-1 cells, and c) E-ras cells. The following variables were introduced: activity with or without coenzymic DNA (50 nM AT), and assay for the inhibitory action of the non-hydrolyzable ATP analog AMP-PNP, a reagent which distinguishes auto- and hetero-poly (ADP-ribosylation) (9). As seen in Fig. 3, confluent CV-1-1 cells exhibited the lowest activity which was not significantly stimulated by AT (50 nM) and not inhibited by AMP-PNP. These results show that in resting non-malignant cells trans-poly (ADP-ribosylation) occurs. In pre-confluent CV-1-1 cells where measurable cell multiplication was detectable, rates of poly ADP-ribosylation were approximately doubled, a rate which was still unaffected by AT ( $50 \mathrm{nM})$ and only marginally inhibited by AMP-PNP, consistent with predominance of trans- or hetero-poly (ADPribosylation). On the other hand malignant (E-ras) cells showed a large stimulation by AT coenzyme and a marked depression by AMP-PNP, indicating a significant contribution of autopoly (ADP-ribosylation), which seems to be a marker for malignant cell proliferation.

Auto-oligo-ADP-ribosylation of the PARP-1 protein and hetero-, or trans-ADP-ribosylation of histone $\mathrm{H}_{1}$ was further discriminated by the determination of ADP-ribose units covalently attached to PARP-1 or histone $\mathrm{H}_{1}$ (4; data not shown). Characteristically, the polymer length did not exceed 20-25 ADP-ribose units attached to PARP-1 (i.e., auto-oligoADP-ribosylation) or an average of 2 ADP-ribose units bound to histones (i.e., hetero- or trans-ADP-ribosylation) as assayed in Calu 6 cells.
Table I. PARP-1 content of cell lines, calculated from kinetics.

\begin{tabular}{lccc}
\hline & & \multicolumn{2}{c}{ PARP-1 } \\
\cline { 3 - 4 } Cell line & $\begin{array}{c}\text { ADPR } \\
\text { pmols }\end{array}$ & $\begin{array}{c}\text { Concentration } \\
(\mathrm{nM})\end{array}$ & $\begin{array}{c}\text { Active } \\
\text { molecules per cell }\end{array}$ \\
\hline 1. E-ras & 400 & 4.0 & $1.20 \times 10^{6}$ \\
2. Calu 6 & 800 & 8.0 & $2.40 \times 10^{6}$ \\
$\begin{array}{l}\text { 3a. CV-1 } \\
\text { (confluent) }\end{array}$ & 73 & 0.75 & $0.23 \times 10^{6}$ \\
$\begin{array}{l}\text { 3b. CV-1 } \\
\text { (non-confluent) }\end{array}$ & 232 & 2.3 & $0.70 \times 10^{6}$ \\
\hline
\end{tabular}

$0.12 \times 10^{6}$ permeabilized cells were incubated for $10 \mathrm{~min}$ in the presence of $100 \mathrm{nM} \mathrm{AT}$ and $3 \mathrm{mM}$ spermine to maximize activity. From the obtained amounts of incorporated ADPR (first column) the corresponding PARP-1 concentrations were derived using a standard curve in which varied concentrations of human PARP-1 (Trevigen) were plotted against the ADPR incorporated after 10-min incubation with $100 \mathrm{nM}$ T and $3 \mathrm{mM}$ spermine. Using Avogadro's number, the number of molecules of PARP-1 per cell was derived from these molarities. For example, in no. 1 (50 $\mu 1$ incubate):

$$
\frac{4 \times 10^{-9} \times 50 \times 10^{-6} \times 6.02 \times 10^{23}}{0.1 \times 10^{6}}=1.2 \times 10^{6}
$$

Duplicate samples were analyzed and the derivation from the mean value did not exceed $\pm 10 \%$.

The results obtained with the LL preparation were corroborated by cellular analysis of poly-ADP-ribosylated proteins by the $2 \mathrm{D}$ gel technique (Fig. 4). Comparison of Calu 6 and CV-1 cells (Fig. 4) illustrates that significantly more protein-bound poly ADP-ribosylated proteins were detectable with the anti-poly (ADP-ribose) antibody in malignantly proliferating cells (Calu 6) than in CV-1 cells. These results are of particular significance since the poly (ADP-ribosylation) took place in intact cells where no externally added NAD but only intracellular NAD was the ADPR donor.

Since our enzyme assays were conducted under $\mathrm{V}_{\max }$ conditions where enzyme protein was linearly proportional to activity (9), we calculated the number of activatable PARP-1 molecules per cell, as shown in Table I. Results are comparable to those given in Figs. 3 and 4, and the general conclusion may be drawn that cancer cell proliferation coincides with a significant increase in activatable PARP-1 molecules per cell.

Analysis of PARP-1 mRNA. The PARP-1 mRNA content of the contact inhibited $\mathrm{CV}-1$ and the fast-growing tumor cells was analyzed by a quantitative real-time PCR assay. Total RNA was isolated from both types of cell and $1 \mu \mathrm{g}$ portions of RNAs were reverse-transcribed as described in Materials and methods. Equal amounts of cDNAs were analyzed by realtime PCR for PARP-1 mRNA content, and the constitutively expressed L19 small ribosomal subunit protein mRNA levels were utilized as internal standards (see Materials and methods). 
A

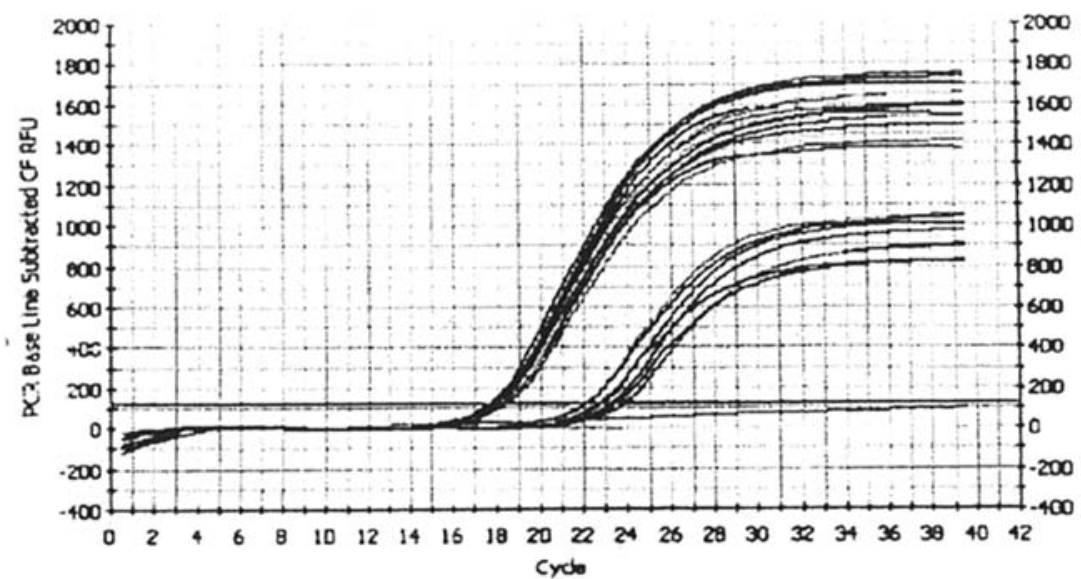

B

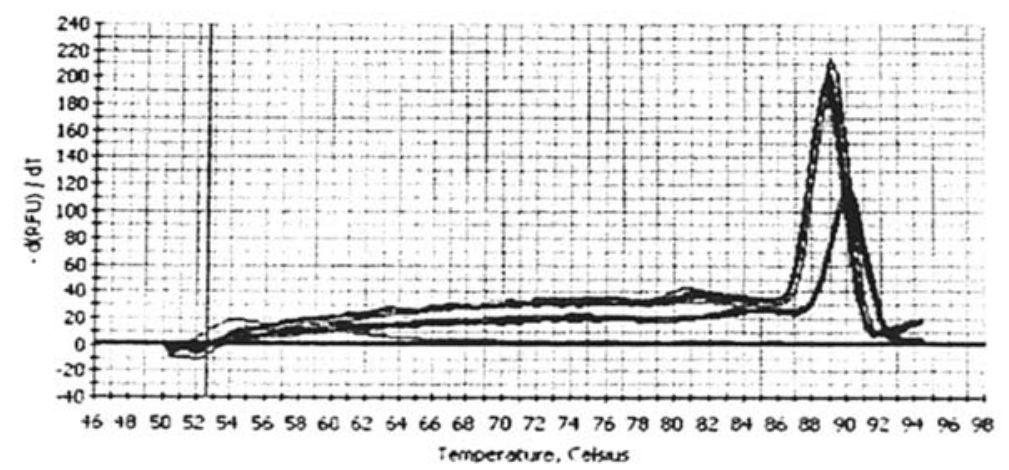

Figure 5. Quantitative analysis of mRNA of PARP-1, extracted from Calu 6 (human lung cancer cells) and human lung fibroblast (see Materials and methods). (A) Real-time PCR recordings of eight parallels of PARP-1 mRNA levels of Calu 6 and human fibroblasts (upper family of curves); lower family of curves: standard mRNA. (B) Melting curves of PCR products.

The real-time PCR curves (Fig. 5) show that the threshold cycle numbers for PARP-1 enzyme are the same for both cell types, indicating that equal amounts of cDNAs were detected throughout the PCR assay. We can surmise that the PARP-1 mRNA levels are the same in both cell types. The melting curve analysis proves that one major PCR product was generated for both PARP-1 and CV-1 cells.

Comparison of rates of malignant proliferation and rates of DNA synthesis. Just as for PARP-1 activity, we compared rates of DNA synthesis of confluent CV-1 cells with preconfluent (proliferating) and highly proliferating E-ras 20 cancer cells (Fig. 6). Similar to results obtained with PARP-1 (Fig. 3), confluent cells showed the lowest rates of DNA synthesis, which was not perceptibly affected by added template DNA. The DNA synthesis rates of preconfluent CV-1 cells were higher and slightly responded with stimulation by template DNA. As expected, permeabilized E-ras 20 cells had the highest rate of stimulated DNA synthesis, which was characteristically dependent on added template DNA. Without template DNA, activity was the lowest in cancer cells. Template DNA could not be replaced by AT, the coenzyme of PARP-1 (data not shown). These results are reminiscent of the strong stimulation of PARP-1 activity by AT (Fig. 3); thus malignant cells behaved as if deficient in

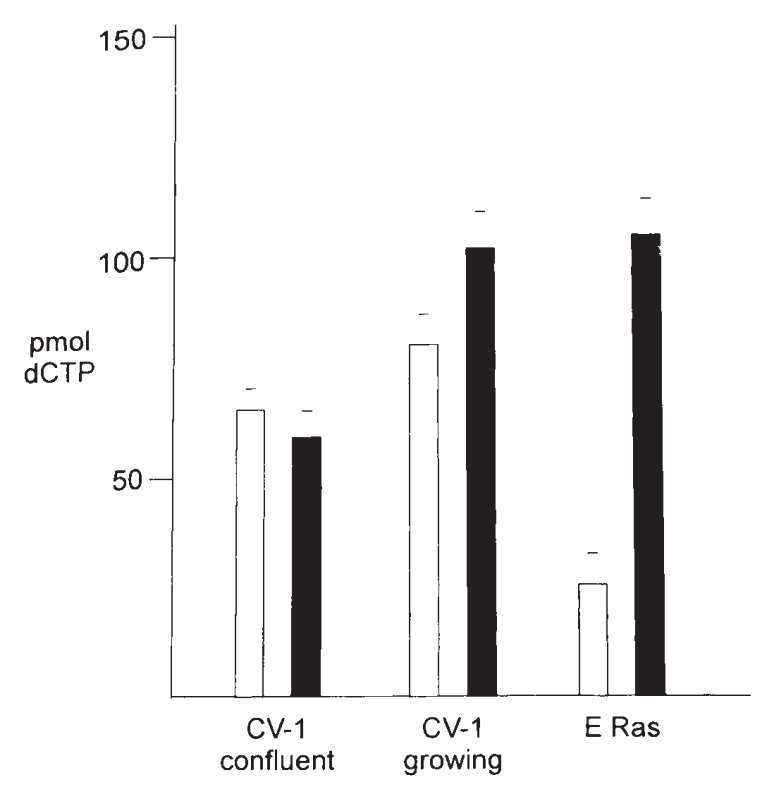

Figure 6. Rates of DNA synthesis in confluent and growing (not contact inhibited) CV-1 cells and E-ras cells. Open bars, no template DNA; shaded bars, + template DNA (10 $\mu \mathrm{g}$ DNAase 1 treated DNA per $50 \mu 1$ incubate). Cell number per test $0.7 \times 10^{6}$ cells $/ 50 \mu 1$. It is essential for the demonstration of the activation by template DNA that $5 \mathrm{mM} \mathrm{MgCl}_{2}$ and $0.5 \mathrm{mM} \mathrm{CaCl}_{2}$ be present, including LL solution and in radioactive nucleotide mixture (see Materials and methods). 
A

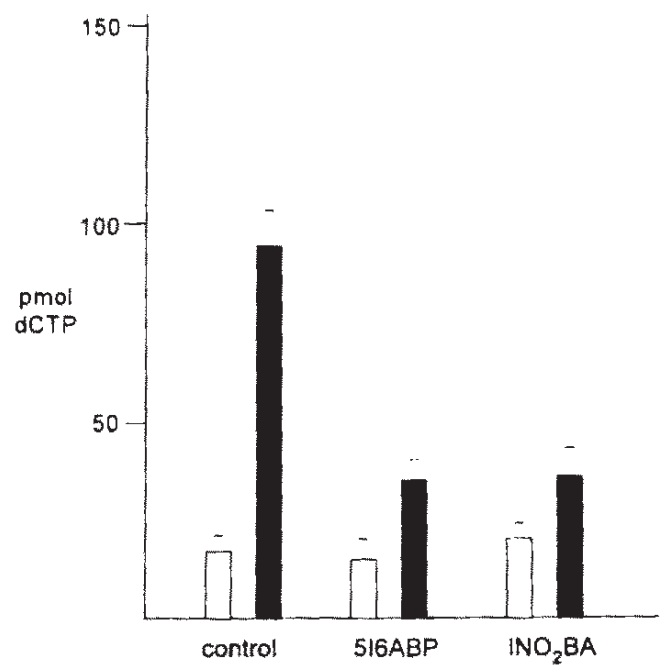

B

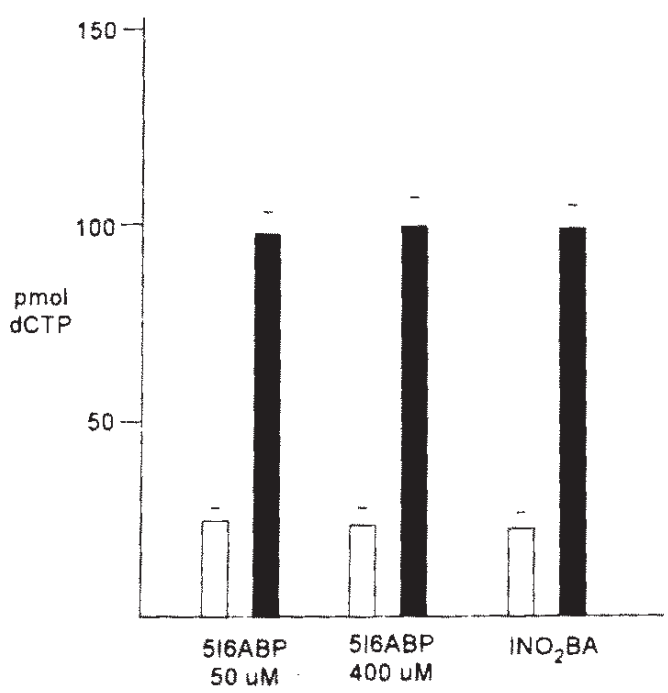

Figure 7. (A) The inhibitory effect of 5-I-6-amino benzopyrone (516ABP) and the prodrug iodonitrobenzamide $\left(\mathrm{INO}_{2} \mathrm{BA}\right)$ exposed for 4 days with intact cells on rates of DNA synthesis in intact E-ras cells $\left(6.7 \times 10^{6}\right.$ cells per test). Open bars, no templatye DNA; shaded bars, template DNA added to the permeabilized assay system (see Materials and methods). Experimental variations are shown in the figure. (B) The absence of effect of PARP-1 drugs added directly to permeabilized E-ras cells performing DNA synthesis. The choice of drug concentrations is based on published results $(1,2)$. $\mathrm{INO}_{2} \mathrm{BA}$ is a prodrug that is selectively reduced to the nitroso product in tumor cells only (1).

PARP-1 coenzyme and template DNA for DNA synthesis. The marked effect of template DNA on DNA synthesis in cancer cells is a novel experimental phenomenon and its analysis is part of on-going research.

The possibility of a causal relationship between PARP-1 activity and rates of DNA synthesis is implied in results shown in Fig. 7A. When a specific inhibitor of PARP-1, i.e., 5-I-6-amino-1,2-benzopyrone (2) or an inactivator of the asymmetric $\mathrm{Zn}^{2+}$ finger of PARP-1, 4-iodo-3-nitrobenzamide, which is a prodrug (1), was preincubated with intact cancer cells, a progressive inhibition of activatable DNA synthesis occurred parallel with inhibition of PARP-1 as reported earlier $(1,2)$. Direct exposure of the DNA synthetase system of permeabilized cancer cells to these tumor-specific drugs had no effect on DNA synthesis, consistent with the evidence illustrated in Fig. 7B, indicating that DNA synthesis appears to be regulated by active PARP-1 in cancer cells. It is important to note that neither of the drugs exerts toxic cellular effects on non-cancerous cells $(1,2)$.

\section{Discussion}

The LL preparation provides an experimental model to study regulation of macromolecular metabolism in cells with the possibility of correlating enzymology with integrated cell function. This technique offers the possibility of identifying cofactors that may have escaped the attention of enzymologists. In the case of PARP-1, our results show that a relatively simple treatment of cancer cells leaves PARP-1 nearly inactive unless $\mathrm{nM}$ concentrations of AT and $\mathrm{mM}$ concentrations of spermine are added, resurrecting PARP-1 activity to $\mathrm{V}_{\max }$. There is no need to produce DNA damage (16), which was thought to be a sine qua non cofactor of PARP-1. The LL preparations open experimental avenues to determine the nature of the DNA-coenzymes of PARP-1, which are extracted from intact cells. The PARP-1 substrate $\mathrm{NAD}^{+}$is also extracted during centrifugal fractionation. However, results shown in this report demonstrate that analyses for poly-ADP-ribosylated proteins by the direct $2 \mathrm{D}$ gel technique in intact cells and enzyme assays of LL preparations yield identical results regarding the increased PARP-1 activity in malignantly proliferating cells, thereby mitigating the possible artificiality of PARP-1 assays in LL-treated cells and bringing them closer to intact cells. We were able to demonstrate that alterations in the rate of transcription of the PARP-1 gene are not responsible for the apparent higher activity or content of PARP-1 in cancer cells. It is of further interest that spermine presents itself as the singularly most powerful cationic activator of PARP-1. We (2) and others (cf. 9) have shown that cancer cells contain very high concentrations of ornithine decarboxylase, and thus the chemical cofactor (spermine) of PARP-1 is produced by malignantly proliferating cells. Other cations $\left(\mathrm{Ca}^{2+}, \mathrm{Mg}^{2+}\right)$ may participate as regulators of smaller cellular oscillations of PARP-1 activity. The overriding inhibition of PARP-1 by ATP $(4,9)$ at the auto-poly (ADP-ribosylation) site explains the inactivity of this enzyme in cells possessing normal bioenergetics, and also clarifies the puzzle regarding the ineffectivity of PARP-1 inhibitors (2) in normal cells where PARP-1 is already suppressed by ATP $(4,9)$, implying abnormal bioenergetics in cancer cells. Analysis of the chain length of oligo-ADP-ribose in LL cells shows that auto-oligoADP-ribosylation is limited to 20-25 units, whereas trans-ADPribosylation is limited with histone $\mathrm{H}_{1}$ to two ADPR units. These results are in good agreement with published in vivo data $(17,18)$; thus the LL technique yields agreement with in vivo analyses. The correlation between PARP-1 activity and increased DNA synthesis in cancer cells represents a problem unresolved in its molecular details which was brought forward by experiments with LL cells. The co-localization of PARP-1 and DNA polymerase $\beta$ in regenerating liver nuclei (19) may indicate the cooperative or regulatory role of PARP-1 in induced cell replication. It is also known that PARP-1 is a component of a multi-protein complex participating in 
differentiation-linked DNA replication (20), supporting our view of an intimate connection between PARP-1 and DNA synthesis. Regulation of gene expression was proposed in 1988 (21) to be a main cellular function of the PARP-1 system. More recently, the role of PARP-1 in chromatin was experimentally supported (22) by its control of transcription, confirming the function of ATP (9) as a regulator of PARP-1 activity.

Results presented here indicate a functional correlation between PARP-1 and DNA synthesis in normal proliferation and especially in malignant cells. Although molecular details of this control system are as yet unknown, our results suggest experimental avenues which have not been formulated in the past. The complexity of DNA synthesis is illustrated in recent reviews $(23,24)$. It now appears feasible to analyze the action of PARP-1 in DNA synthesis.

A tentative working hypothesis is proposed that allows broader rationalization of our results. The identical rates of PARP-1 mRNA synthesis in non-cancerous and malignant cells indicates that biochemical differences between normal and cancerous cell proliferation may be traced to events occurring after the entry of PARP-1 into the nucleus following its synthesis in the cytoplasm. The exclusivity of trans-poly (ADP-ribosylation) in non-growing normal cells - as we show here - may indicate an association of PARP-1 with histones or other non-histone proteins of nuclei of normal cells. In contrast, the preponderance of self-association of PARP-1 $(8,9)$ producing auto-poly (ADP-ribosylation) appears to be a speciality of malignantly proliferating cells. Nuclear autoand hetero-associations of PARP-1 are a probable measure of structural changes in chromatin, distinguishing malignant and non-malignant proliferation.

\section{Acknowledgements}

This work was supported by NIH grants HL 59693 and HL 35561, OTKA grant TO 42473, and BiPar Sciences Inc. We are indebted to W.E. Tidyman for preliminary immunochemical tests for PARP-1. Our thanks are due to Clementina Kun for her help in preparing the manuscript. A preliminary report of this work was presented at the 8th International Symposium on Molecular Medicine, Hersonissos, Crete, October 2005.

\section{References}

1. Bauer PI, Mendeleyev J, Kirsten E, Comstock JA, Hakam A, Buki KG and Kun E: Anti-cancer action of 4-iodo-3-nitrobenzamide in combination with butionine sulfoximine: inactivation of poly(ADP-ribose) polymerase and tumor glycolysis and the appearance of a poly(ADP-ribose) polymerase protease. Biochem Pharmacol 63: 455-461, 2002.

2. Bauer PI, Kirsten E, Young LJT, Varadi G, Csonka E, Buki KG, Mikala G, Hu H, Comstock JA, Mendeleyev J, Hakam A and Kun E: Modification of growth related enzymatic pathways and apparent loss of tumorigenicity of a ras-transformed bovine entothelial cell line by treatment with 5-iodo-6-amino-1,2benzopyrone $\left(\mathrm{INH}_{2} \mathrm{BP}\right)$. Int J Oncol 82: 239-252, 1996.

3. Curtin IJ: PARP inhibitors for cancer therapy. Expert Rev Mol Med 7: 1-20, 2005.

4. Bauer PI, Kenesi E, Mendeleyev J and Kun E: The influence of ATP on poly(ADP-ribose) metabolism. Int J Mol Med 16: 321-324, 2005.
5. Gallmeier A and Kern SE: Absence of specific cell killing of BRCA2-deficient human cell line CAPANI by poly(ADP-ribose) polymerse inhibition. Cancer Biol Ther 10: 4, 2005.

6. Hanahan D and Weinberg R: The hallmarks of cancer. Cell 100: 57-70, 2000.

7. Amé J-C, Spelenhauer C and De Murcia G: The PARP superfamily. Bioessays 26: 882-8893, 2004.

8. Kun E, Kirsten E and Ordahl CP: Coenzymatic activity of randomly broken or intact double stranded DNAs in auto- and histone $\mathrm{H} 1$ trans-poly-ADP-ribosylation, catalyzed by poly (ADPribose) polymerase (PARP-1). J Biol Chem 277: 39066-39069, 2002.

9. Kun E, Kirsten E, Mendeleyev J and Ordahl CP: Regulation of the enzymatic catalysis of poly (ADP-ribose) polymerase by dsDNA, polyamines, $\mathrm{Mg}^{2+}, \mathrm{Ca}^{2+}$, histones $\mathrm{H}_{1}$ and $\mathrm{H}_{3}$, and ATP. Biochemistry 43: 210-216, 2004.

10. Miller MR, Castellot JJ and Pardee AP: A permeable cell preparation for studying macromolecular systems. DNA synthesis and the role of deoxyribonucleotides in $\mathrm{S}$ phase initiation. Biochemistry 17: 1073-1080, 1978.

11. Castellot JJ Jr: Lysolecithin-permeabilized animal cells as a tool for studying cell growth and metabolism. In: Introduction of Macromolecules into Viable Mammalian Cells. Baserga R, Croce C and Rovera GA (eds). Liss Inc., NY, pp297-324, 1980.

12. Kirsten E, Kun E, Mendelyev J and Ordahl CP: Epigenetics protocols. Tollefsbol TO (ed). Humana Press, NJ. Methods Mol Biol 287: 137-149, 2004.

13. Amé J-C, Rolli V, Schreiber A, Niedergang C, Apiou A, Decker P, Muller S, Höger T, Ménissier-De Murcia J and De Murcia G: PARP-2, a novel mammlian DNA damagedependent poly(ADP-ribose) polymerase. J Biol Chem 274: 17860-17868, 1999.

14. Koh DW, Coyle DL, Mehta N, Ramsinghani S, Kim H, Slama JT and Jacobson MK: SAR analysis of adenosine diphosphate (hydroxy methyl) pyrrolidine diol inhibition of poly (ADP-ribose) glydohydrolase. J Med Chem 46: 4322-4333, 2003.

15. Slama JT, Aboul-Ela N and Jacobson MK: Mechanism of inhibition of poly (ADP-ribose) glycohydrolase by adenosine diphosphate (hydroxymethyl) pyrrolidine diol. J Med Chem 38: 4333-4336, 1995.

16. De Murcia G and Shall S: From DNA Damage and Stress Signals to Cell Death: Poly ADP-Ribosylation Reactions. Oxford University Press, New York, 2000.

17. Kidwell WR and Mage MG: Changes of poly(adenosine diphosphoribose) polymerase in synchronous HeLa cells. Biochemisty 15: 1213-1217, 1976.

18. Burzio LO, Riquelme PT and Koide SS: ADP-ribosylation of rat liver nuclosomal core histones. J Biochem 254: 3029-3037, 1979.

19. Kirsten E, Minaga T and Kun E: Coincidence of subnuclear distribution of poly (ADP-ribose) synthetase and DNA polymerase $\beta$ in nuclei or normal and regenerating liver. FEBS Lett 139: 117-120, 1982.

20. Simbulon-Rosenthal CM, Rosenthal DS, Hilz H, Hickey R, Malkas L, Applegreen N, Wu Y, Bers G and Smulson M: The expression of poly(ADP-ribose) polymerase during differentiationlinked DNA replication reveals that it is a component of the multiprotein DNA replication complex. Biochemistry 35: 11622-11633, 1996.

21. Kun E: Probable macromolecular mechanism of gene regulation by adenosine diphosphoribosyl transferase. In: Proceedings of the First International Symposium on Post-transcriptional Modification of Proteins and Ageing. Zappia UV (ed), University of Naples. Plenum Press, pp613-626, 1988.

22. Kim MY, Mauro S, Gévry N, Lis JT and Kraus WL: NAD+dependent modulation of chromatin structure and transcription by nucleosome binding properties of PARP-1. Cell 119: 803-814, 2004.

23. Kunkel TA: DNA replication fidelity. J Biol Chem Minireview Compendium 00: 16895-16898, 2004.

24. Stauffer ME and Chazin WJ: Structural mechanisms of DNA replication repair and recombination. J Biol Chem Minireview Compendium 00: 30195-30198, 2004. 